\title{
Beyond Social Acceptability: Applying Lessons from CCS Social Science to Support Deployment of BECCS
}

\author{
Clair Gough $^{1} \cdot$ Sarah Mander ${ }^{1}$
}

Published online: 23 November 2019

(C) The Author(s) 2019

\begin{abstract}
Purpose of Review This paper assesses social science research relating to BECCS and considers the applicability of research on CCS to BECCS.

Recent Findings In recent years, social science research on CCS and BECCS has gone beyond an evaluation of public acceptance to provide a more nuanced analysis of the wider social political, ethical, and governance contexts in which large-scale deployment might be achieved. This raises issues at global, local, and regional scales, requiring a wide array of methods and approaches. Summary Awareness of the scale and urgency needed to act on climate change is growing and the role of BECCS in delivering carbon dioxide removal forms a central argument for the use of this family of technologies. Here, framing becomes a critical factor in how society responds to BECCS technologies and we argue that making the case for BECCS as a means of extending mitigation to make a 'net zero' goal achievable could be the key to its acceptable and sustainable deployment.
\end{abstract}

Keywords CCS · BECCS $\cdot$ Carbon dioxide removal $($ CDR $) \cdot$ Negative emissions $\cdot$ Social responses $\cdot$ Acceptability

\section{Introduction}

Carbon capture and storage, or CCS, is a set of technologies which capture, transport, and store $\mathrm{CO}_{2}$ over the long term in geological formations, either onshore or offshore. The approach can be applied in the context of a variety of $\mathrm{CO}_{2}$ sources, including fossil- or biomass-fuelled power generation (BECCS) and industry. Although it was featured as a component of proposed climate mitigation portfolios for nearly two decades, CCS remains an emerging technology. Globally, there are currently only 18 large-scale CCS projects in operation (and a further 25 planned or under construction [1]) but it is far from widely deployed at a commercial scale and many of the existing projects are linked to enhanced oil recovery (EOR) rather than dedicated $\mathrm{CO}_{2}$ storage applications. With the $1.5^{\circ} \mathrm{C}$ aspiration set out in the Paris agreement focusing

This article is part of the Topical Collection on Deep Decarbonization: $B E C C S$

Clair Gough

clair.gough@manchester.ac.uk

1 Tyndall Centre for Climate Change Research, Department of Mechanical, Aerospace and Civil Engineering, University of Manchester, Manchester M13 9PL, UK efforts for ambitious carbon reductions across all economic sectors, and the prospect of delivering carbon dioxide removal $(\mathrm{CDR})^{1}$ through coupling biomass energy with CCS, there are signs that the technology is picking up momentum. The implementation of BECCS depends on establishing CCS infrastructure to capture, transport, and store $\mathrm{CO}_{2}$; societal responses to BECCS relate to each stage of the CCS chain, to the biomass feedstocks that might be used, and to the principle of using it to deliver a net reduction in $\mathrm{CO}_{2}$ (negative emissions) as part of a strategy to mitigate against climate change. Furthermore, there remain political, governance, economic, and investment challenges in establishing CCS infrastructure and extending the technology to BECCS applications will introduce additional issues in these areas.

In this paper, we reflect on the contribution of social science research to informing the debate around the implementation of CCS and BECCS technologies, over the past five years. Social science research into CCS has developed alongside technical, scientific, and engineering studies from the outset, with publications on possible public reactions to the technology dating

\footnotetext{
${ }^{1}$ Carbon dioxide removal (CDR), greenhouse gas removal (GGR), and negative emissions technologies (NETs) are terms that are used, often interchangeably, to describe the family of approaches with the potential to deliver net reductions in atmospheric $\mathrm{CO}_{2}$ concentration. In this paper, we use the term "CDR" throughout.
} 
back to the early 2000 s (e.g., $[2,3])$. It is important to go beyond understanding public perceptions of a technology and acknowledge the diversity of social responses, such as uncertainty about a technology or risk awareness, and the underlying reasons for these responses. Thus, social responses to CCS and BECCS are shaped by factors which affect people and their values, to the social context in which a technology is to be deployed (e.g., institutions), and to the characteristics of the technology and its potential location. The last five years has seen more analysis into how the wider social acceptability of CCS technology and its deployment might be improved, introducing concepts such as social licence to operate.

Recent reviews have been published relating to public perceptions of CCS [4], carbon capture and utilisation (CCU) [5], BECCS [6 ], and CDR, covering all disciplines [7], and focusing on the social and political dimensions of BECCS and afforestation as greenhouse gas removal approaches [8]. The present paper builds on these reviews, which demonstrate the strong analytical base from which to build communications material and procedural good practice for establishing projects, to explore what is known about social responses to BECCS from research focused on BECCS and from the wider CCS literature. We begin in the 'Acceptability in Context' section by considering how context affects acceptability, in terms of sources of $\mathrm{CO}_{2}$ and geographical location, from different theoretical perspectives. We include both CCS and BECCS in the 'Introduction' section as there is much to be learnt from literature relating to CCS. Social science research has begun to address BECCS specifically in the past five or six years but, in the absence of proposed projects, has initially focused on wider issues around the potential for the sustainable deployment BECCS, including issues relating to policy and governance and ethics and its role within climate change mitigation. Thus, the 'From CCS to BECCS and Greenhouse Gas Removal' section looks at these broader issues that become more pertinent as the context moves away from a focus on CCS for climate change mitigation at a project-based level to a broader carbon dioxide removal (CDR) agenda associated with large-scale BECCS deployment. The 'Conclusions' section provides a reflection on how this body of literature has evolved to provide a more nuanced understanding that goes beyond assessing public acceptance to a consideration of the wider context and framings which apply.

\section{Acceptability in Context}

\section{BECCS is Part of the CCS Family}

BECCS is a specific application of CCS where the $\mathrm{CO}_{2}$ is captured from a process using a biomass feedstock; it was initially conceived as a stop-gap solution which could allow more ambitious climate change targets to be achieved. More recently, the need for greater levels of emission reduction, driven by the $1.5^{\circ} \mathrm{C}$ imperative combined with an understanding of the potential role for CCS in reducing emissions across the whole economy and its potential to deliver CDR, has changed the policy context and BECCS is now a mainstay of proposed climate mitigation portfolios. Not surprisingly, given that CCS was more commonly associated with fossil-fuelled electricity generation, there has historically been more work looking at CCS from fossil sources or which does not distinguish between different types of CCS. One of the earliest studies, which does distinguish between different sources of $\mathrm{CO}_{2}$, [9], found that fossil fuel sources of $\mathrm{CO}_{2}$ were perceived less favourably by survey respondents than industrial or bioenergy sources. Whilst research has started to consider different applications for carbon capture (e.g., carbon capture and utilisation (CCU) [10]), we found that BECCS is often compared with other CDR technologies (e.g., [11]), or other sources of $\mathrm{CO}_{2}$, (e.g., $\left.[12,13]\right)$ rather than considered on its own. More favourable responses to CCS have been observed when it is combined with bioenergy and increased support has been reported for $\mathrm{CCU}$ - notably amongst climate sceptics, for whom addressing concerns about waste carried greater traction than climate change mitigation [10]. Utilisation of captured $\mathrm{CO}_{2}$ for enhanced oil recovery (EOR) could provide a revenue stream to reduce the costs and accelerate CCS infrastructure development $[14,15]$. However, the potential scale of $\mathrm{CO}_{2}$ reductions which could be made through CCU options, including EOR, remains limited (Mac Dowell et al., 2017). Furthermore, the use of captured $\mathrm{CO}_{2}$ as a feedstock for industrial processes (CCU) presents its own set of issues from a societal and governance perspective (e.g., [16]), and Jones et al. [5, 17] explore some of these issues across three dimensions of social acceptance (socio-political, market, and community).

Storage has been shown to be the most contentious part of the CCS chain (e.g., [10, 18-20]) whereby people living closer to storage sites express a lower acceptance of CCS [19] and offshore storage is more likely to be seen as acceptable (e.g., [21]). These findings are relevant for BECCS, and acceptance of storage has been shown to depend on national policy contexts, local industry and identity, and perceived risks and benefits (e.g., [18]). The greater support observed for CCU may arise because capture is the most accepted element of the CCS chain. CCU brings the potential to offset capture costs, is seen as an incremental change to existing industrial processes (e.g., [22]), and is viewed in relation to perceptions of the industry and local history, in contrast to $\mathrm{CO}_{2}$ transport, which affects multiple communities along its route [23•] and storage, which is seen as the most novel element of CCS [17].

There is, as yet, little research that has been undertaken on BECCS compared with other forms of CCS. Drawing on experience and expertise with CCS, Dowd et al. [6•] reflect on the need for a social licence, trust and procedural fairness, and provision of information and sources (e.g., the media). Furthermore, views of BECCS reflect perceptions of the 
bioenergy and particularly the need for sustainable biomass with associated environmental and food implications, as well as perceptions of CCS (e.g., [24, 25]).

\section{Geographical Contexts and Place-Based Studies}

Whilst research into BECCS is in its infancy and there is limited deployment of the technology, research into CCS highlights the influence of geographical context on the social responses. CCS studies have explored responses in countries where there are already operational CCS projects e.g., Canada [26] and Norway [27], where there is policy interest in CCS e.g., the UK [18, 22, 28-30], the wider Nordic region [21], and New Zealand [31], and where there has been opposition to CCS projects e.g., The Netherlands [32] and Germany [9, 19, $33,34]$. These studies emphasise the importance of understanding the specific social context for deployment as a dynamic interaction of people, places, and events which drive public perceptions. Familiarity with the technology, or other related industries, influences perceptions or risk and benefits (e.g., $[26,35]$ ), particularly in terms of the trust in an established local industry and the local policy context under which those industries are governed (e.g., [22]).

Cross-national studies have explored how different factors, e.g., geographical, social, psychological and informational [10], and cultural [36], affect views on CCS amongst lay publics. Karimi et al. [36] found that although cultural characteristics did influence public perceptions of CCS and its potential risks, responses were unlikely to be predicted by cultural factors alone, highlighting the critical role of contingent factors at a local scale. Whitmarsh et al. [10] found marked differences in awareness of and support for CCS between the countries included in the study (Netherlands, Canada, Norway, USA, UK). The greatest support was reported in the UK where, for example, storage sites will be located offshore and the lowest in the Netherlands, which has previously seen high-profile opposition to a proposed project [37].

With 20 projects planned or operational (GCCSI), China is a key region for global CCS deployment; here, CCS costs are likely to be much lower than, for example, in the EU, and Chen et al. suggest that it could be economically competitive in China, without the need for support, by 2030 [38]. Despite this, there is limited social research published relating to this region - what there is shows that there is very low awareness of CCS amongst lay publics in China and limited support for the technology $[39,40]$.

\section{Methods and Theoretical Contexts}

Research has drawn on varied theoretical concepts including social licence to operate $[22,41]$, media representations (e.g., $[42,43])$, and justice and human rights (e.g., [44]). There has been a strong emphasis on risk and risk communication;
L'Orange Siego et al. [26] highlight the importance of mental models and knowledge to draft risk communication material, and the importance of benefit perceptions and trust, the importance of stakeholder engagement and experience of other technologies, findings echoed by many $[4,19,31,36,45,46]$.

The potential for public acceptance of CCS and the factors which impact upon it have been explored using a variety of methods, depending on the theoretical framework underpinning the research. For example, qualitative methods including focus groups [31] support an in-depth understanding of alternative viewpoints and the reasons behind different responses, whereas surveys (e.g., $[12,19])$ provide a more superficial analysis from an extensive sample of people. In a recent study, Bellamy et al. [25] used a mixed methods approach, presenting alternative policy scenarios to different groups and assessing perceptions of BECCS using a limited survey and group discussions to understand the differences between the groups. Given the emergent nature of CCS, and lack of familiarity with the technology, analogies have been used for CCS and to explore how people's attitudes are shaped by reference to other technologies e.g., fracking $[22,47]$ and nuclear [18].

\section{From CCS to BECCS and Greenhouse Gas Removal}

\section{Extending Mitigation}

The 2015 Paris Agreement, and its aspiration to limit global average temperature rise to $1.5^{\circ} \mathrm{C}$, introduces a new urgency and ambition to climate policy. Conventional mitigation approaches may be complemented by methods to remove carbon dioxide from the atmosphere, as 'net zero' $\mathrm{CO}_{2}$ becomes the policy benchmark. In principle, by removing atmospheric $\mathrm{CO}_{2}$ at a level that matches emissions from 'hard to abate' sectors (such as aviation, for example), CDR approaches could compensate for these residual emissions to make a 'net zero' pathway achievable. Afforestation and BECCS are the two primary CDR approaches currently represented in integrated assessment models (IAMs) which inform the IPCC on pathways to deliver Paris temperature goals. The central role for $\mathrm{CDR}$ in achieving both the $1.5^{\circ} \mathrm{C}$ and the $2^{\circ} \mathrm{C}$ ambition introduces a new imperative to establish CCS as part of a sociotechnical imaginary [48] in which the policy aspiration of 'net zero' plays an important role in the framing and implementation of CCS, BECCS (and other CDR), technologies $[49,50]$.

The notion of geoengineering - the intentional manipulation of the earths' climate - is a challenging and controversial concept which conventionally distinguishes between CDR and solar radiation management (SRM) approaches [51, 52]. Fossil CCS has not typically been identified as a geoengineering approach; however, its role in CDR through 
BECCS places it within a geoengineering framing [52]. Thus, some studies exploring ethical, social, and policy implications of BECCS as a CDR method analyse the approach as a method of geoengineering (e.g., [44, 53, 54]). Others, however, make the case for separating BECCS (and other CDR approaches) from a geoengineering 'climate recovery' framing, arguing that it is better identified as an 'emission offsetting' strategy [55] to complement mitigation in a way that is comparable to existing 'enhancement of sinks' policies [56] and consistent with a view of CDR as SRM's less-risky cousin [57•]. This conceptual distinction becomes important, not just for how CDR can be incorporated into policy frameworks [56] but also when considering the ethical and governance implications [58] and, consequently, how it is perceived by different actors [25, 58]. This distinction is, in part, predicated on whether CDR is used to enable deeper emission cuts in the near term or to allow an 'overshoot' in carbon budgets. In this sense, BECCS can be seen as a means of separating abatement from emissions over time, by allowing $\mathrm{CO}_{2}$ emissions to be 'removed' from the atmosphere at a future date (allowing an overshoot), or separated in space by potentially geographically extensive supply chains [59] (extended mitigation framing).

The IAMs that inform the IPCC pathways and, hence, the global policy dialogue, are central to the debate about the potential role of CDR measures in relation to carbon budgets and have attracted significant attention in the literature, which highlights the uncertainties and ethical implications associated with representing global-scale CDR through BECCS, the level of influence that this might have on the policy agenda and the assumptions made within the models [50, 60-66]. The key is that BECCS and CDR are not alternatives to conventional emission mitigation; the magnitude of CDR required to meet carbon budgets associated with the Paris Agreement is highly challenging even with ambitious emission reductions in the near term [20, 63, 67, 68].

Furthermore, there is a mismatch between how BECCS may be viewed at a national or regional level and its significance within global analyses [69]. This gap between global, regional, and national priorities, combined with complex and pervasive non-technical challenges [70], places limitations on the potential for BECCS $[61,66]$. With limited awareness of BECCS and CDR beyond expert communities, and very little empirical research into potential public responses, understanding the broader ethical, political, and governance issues will be critical to how societies view the 'acceptability' of CDR through BECCS.

\section{BECCS, CCS, and Ethics}

The literature in this area calls for a more democratic process, one which opens up critical discussion of wider implications, differentiating by scale rather than 'technology', to consider social, ethical, and political impacts of different levels of deployment and decision making (for example, 58, 59). Ethical mapping of CCS has identified justice, prevention of harm, and technoscientific and regulatory competence as potential faultlines or areas of contention [71-73]. With extended BECCS supply chains, where biomass feedstock and storage of $\mathrm{CO}_{2}$ potentially takes place across multiple countries and continents, in addition to technical and sustainability challenges $[20,74]$, there are deep underlying ethical issues associated with its implementation [70]. Separating the emission and removal of $\mathrm{CO}_{2}$ spatially and temporally further increases the ethical implications, particularly in terms of inter- and intra-generational justice.

Concerns persist that the promise of CCS and BECCS might allow society to continue to fail to adequately address the causes of climate change [58, 63, 67]. The potential for CDR approaches, and BECCS in particular, to deter or obstruct mitigation in the near term is widely addressed. This presents a moral hazard, of which Lenzi identifies three types presented by CDR: obstructing mitigation, taking a climate policy 'gamble', and exaggerated potential (hubris) [57]. The complexities of understanding the issue of mitigation deterrence have been further explored from a cultural political economy perspective [75].

\section{Governance Implications and Policy Responses}

Introducing bioenergy feedstocks to the CCS process will require advanced and innovative regulatory frameworks to manage BECCS' potential deployment at a scale consistent with carbon budget constraints. Delivering genuine 'negative emissions' with a sustainable use of biomass brings an additional layer of complexity to maintain multiple sustainability goals (such as food security, ecosystem and biodiversity impacts, water availability inter alia) and recognise conflicting values [20, 70, 76, 77].

A recent special issue on the politics and governance of 'negative emission technologies' explores wide-ranging issues in this field [78], including the potential for mitigation deterrence $[57 \bullet, 75]$ and the need to develop policies which mitigate against direct or indirect impacts to social and natural systems, paying attention to equity and justice, particularly in the context of the potentially significant role of developing countries [44, 60]. Geden and Scott et al. argue that largescale 'comprehensive' $\mathrm{CO}_{2}$ removal challenges current lowcarbon policies at an EU level, suggesting that a more 'limited' role in delivering 'net zero' emissions in the coming decades is likely to gain more traction than a longer-term 'net negative' framing [49, 50, 79, 80].

There are currently no international policy mechanisms to support the implementation of CDR approaches or to incentivise the financing of projects and protect against undesirable sustainability implications $[81,82]$. Consideration of trade-offs between sustainability goals and CDR potential will impact supply chain configurations [74] and new regulatory 
frameworks should account for the diverse and interconnected impacts of BECCS. To achieve effective CDR, international standardised regulatory frameworks must be in place to monitor, report, and verify (MRV) carbon flows across projects [83]. Challenges with carbon accounting arise with BECCS supply chains crossing sectoral and national boundarieshow to allocate and ensure genuine effective CDR is further complicated by temporal aspects associated with carbon sequestered in biomass [84]. Other literatures explore the possible mechanisms through which BECCS could be incentivised or credited [83, 85-87], the potential relevance of existing policies exploiting co-benefits (such as utilising local waste products) [82] and how different policy approaches might influence public opinion or support [25, 88]. McLaren et al. (2019) recommend that to avoid a mitigation deterrence effect, policies relating to CDR should be separated from mitigation across four areas: defining targets, offsetting and emission trading, incentivisation, and modelling and evaluation [89].

\section{Conclusions}

There is a large body of literature presenting research on social responses to CCS. As the social science on CCS and BECCS technologies matures, analysis moves beyond assessments of 'acceptance' or 'public perceptions' to provide a more nuanced and holistic understanding of the societal impacts and contexts. Recognising how different cultural, social, political, ethical, and governance contexts shape the wider sociotechnical environment can contribute to a more sustainable implementation and the 'responsible development' [8] of BECCS technologies. Fostering acceptability (that is, the quality of being acceptable) is one element of achieving a social licence and establishing emergent technologies in a 'fair and competent' manner [90], in which the role of citizens is neither passive nor static. However, CCS is currently deployed in only a few locations and awareness of the technologies remains very low worldwide. Support or opposition for CCS cannot be predicted [10], its acceptability depends on when, where, at what scale, and how it might be implemented.

For new technologies to be successfully deployed at scale, they have to be acceptable to wider society. Understanding what constitutes acceptability and how it can be facilitated in a way that is inclusive and transparent is the first step to ensure that technologies work within and for society, in all its complexity. To make good decisions with sustainable outcomes requires an alignment between social, political, and technical priorities, an understanding of trade-offs, and the ability to navigate across conflicting goals. The social science research described here helps us to unpack the different dimensions of acceptability relating to CCS and BECCS (i.e., social, legal, ethical, political, environmental) but also supports greater understanding of how 'acceptable' technologies may thrive or fail.
As the scale of the climate change mitigation challenge grows, and greater policy ambitions combine with a continued lack of progress in decarbonisation of the wider energy system, including heat, transport, and industry, there is a growing emphasis on the potential role for CCS. CCS now is not only seen as an essential means of reducing emissions but also the possibility of delivering carbon dioxide removal through its use with biomass feedstocks expands the potential for the CCS technologies and potentially allows greater emission reductions in the power sector to compensate for sectors which are harder to abate. The $1.5^{\circ} \mathrm{C}$ and 'net zero' framings change the deployment landscape for CCS. However, progress on deploying CCS infrastructure remains slow; a renewed sense of urgency elevates the need to understand the CCS and BECCS innovation systems in order to establish the infrastructure, with enhanced social learning from near-term deployment informed by context-specific research. There is an urgent need to integrate research into the social and political implications of large-scale bioenergy with that relating to CCS, taking analysis of BECCS beyond the separate literatures. With little familiarity within lay publics about CCS, BECCS is even less familiar - not surprising perhaps that social science literature is directed more towards global issues, such as ethics and governance associated with using BECCS to deliver negative emissions, than on potential responses at a community level. Moreover, with the potential for extended supply chains spanning multiple locations, BECCS projects are likely to affect multiple 'host' communities.

The wider framing which extends the role of CCS/BECCS beyond one of conventional mitigation brings opportunities for more empirical work to broaden participation in addressing some of the bigger questions around BECCS and CDR. Its prominence in IAMs has raised the profile of BECCS as a critical means of delivering $1.5^{\circ} \mathrm{C}$-consistent emission pathways but the socio-political dimensions of BECCS and CDR are poorly represented in these models. There is much that social science can contribute to improving the understanding and representation of non-technical issues, for example through methods to support the co-production of knowledge and which make normative aspects of modelling approaches more explicit (see [60]).

As awareness of the scale and urgency needed to act on climate change is becoming more widespread, so is the recognition that systemic change is needed - even with the potential to deliver CDR from approaches such as BECCS. Against this backdrop, the 'extended mitigation' concept can be constructive-BECCS is not an alternative to 'conventional mitigation'; without very deep cuts in emissions, CDR measures will not be sufficient to bring atmospheric concentrations down in line with $1.5^{\circ} \mathrm{C}$ or to deliver 'net' $\mathrm{CO}_{2}$ removal at a global scale. Here, language and framing become important; if CDR becomes part of the net zero framing, rather than as a conventional 'offsetting' measure, it can become part of a 
wider, more integrated, and fully accounted strategy. There is a strong case for pursuing BECCS as part of the route to net zero $\mathrm{CO}_{2}$, enabling a focus on decarbonisation, reducing the mitigation deterrent potential and working with current policy paradigms $[49,79]$. With many questions unanswered around the potential role for CCS/BECCS, there is a huge potential for social science to guide the path towards more sustainable climate futures. The contexts and details of deployment are critical and without an understanding of the consequences of these wider effects, CCS, and ultimately BECCS, will struggle to become acceptable.

Acknowledgement We gratefully acknowledge the head start given to this paper from the work of Waller et al. [8] in collating a large body of literature in this area.

Funding Information Clair Gough and Sarah Mander declare this work has been funded by the EPSRC (EP/PO26214/1), UKCCSRC (CG and SM), and the Natural Environment Research Council (NE/P019951/1) FABGGR (CG).

\section{Compliance with Ethical Standards}

Conflict of Interest The authors declare that they have no conflict of interest.

Human and Animal Rights and Informed Consent

This article does not contain any studies with human or animal subjects performed by any of the authors.

Open Access This article is distributed under the terms of the Creative Commons Attribution 4.0 International License (http:// creativecommons.org/licenses/by/4.0/), which permits unrestricted use, distribution, and reproduction in any medium, provided you give appropriate credit to the original author(s) and the source, provide a link to the Creative Commons license, and indicate if changes were made.

\section{References}

Papers of particular interest, published recently, have been highlighted as:

- Of importance

1. GCCSI. Global status report. Gobal CCS Insitute; 2018.

2. Gough C, Taylor I, Shackley S. Burying carbon under the sea: an initial exploration of public opinions. Energy Environ. 2002;13: 883-900.

3. Lenstra WJ, Engelenburg BCW, editors. Climate policy, $\mathrm{CO}_{2}$ storage and public perception. Greenhouse Gas Control Technologies: Proceedings of the Fifth International Conference on Greenhouse Gas Control Technologies. Cairns, Autrsalia: CSIRO Publishing; 2001

4. L'Orange Seigo S, Dohle S, Siegrist M. Public perception of carbon capture and storage (CCS): a review. Renew Sust Energ Rev. 2014;38(0):848-63.

5. Jones CR, Olfe-Kräutlein B, Naims H, Armstrong K. The social acceptance of carbon dioxide utilisation: a review and research agenda. Front Energy Res. 2017;5(11).
6. Dowd A-M, Rodriguez M, Jeanneret T. Social science insights for the BioCCS industry. Energies. 2015;8(5):4024-42 This paper provides a comprehensive review of social science research relevant to BECCS deployment and lessons that can be learned from other energy- and resource-based industries.

7. Minx JC, Lamb WF, Callaghan MW, Bornmann L, Fuss S. Fast growing research on negative emissions. Environ Res Lett. 2017;12(3):035007.

8. Waller L, Rayner T, Chilvers J, Gough C, Lorenzoni I, Jordan A, et al. Contested framings of greenhouse gas removal and its feasibilities: social and political dimensions. WIREs Clim Chang. 2019; under review.

9. Duetschke E, Schumann D, Pietzner K, Wohlfarth K, Höller S. Does it make a difference to the public where $\mathrm{CO}_{2}$ comes from and where it is stored? An experimental approach to enhance understanding of CCS perceptions. Energy Procedia. 2014;63:69997010.

10. Whitmarsh L, Xenias D, Jones CR. Framing effects on public support for carbon capture and storage. Palgrave Commun. 2019;5(1): 17.

11. Cummings CL, Lin SH, Trump BD. Public perceptions of climate geoengineering: a systematic review of the literature. Clim Res. 2017;73:247-64.

12. Braun C, Merk C, Pönitzsch G, Rehdanz K, Schmidt U. Public perception of climate engineering and carbon capture and storage in Germany: survey evidence. Clim Pol. 2018;18(4):471-84.

13. Buck HJ. Rapid scale-up of negative emissions technologies: social barriers and social implications. Clim Chang. 2016;139(2):155-67.

14. Kolster C, Masnadi MS, Krevor S, Dowell NM, Brandt AR. $\mathrm{CO}_{2}$ enhanced oil recovery: a catalyst for gigatonne-scale carbon capture and storage deployment? Energy Env Science. 2017;10:2594-608.

15. Edwards RWJ, Celia MA. Infrastructure to enable deployment of carbon capture, utilization, and storage in the United States. Proc Natl Acad Sci. 2018;115(38):E8815-E24.

16. Bruhn T, Naims $\mathrm{H}$, Olfe-Kräutlein B. Separating the debate on $\mathrm{CO}_{2}$ utilisation from carbon capture and storage. Environ Sci Pol. 2016;60:38-43.

17. Jones CR, Olfe-Kräutlein B, Kaklamanou D. Lay perceptions of carbon dioxide utilisation technologies in the United Kingdom and Germany: An exploratory qualitative interview study. Energy Res Soc Sci. 2017;34:283-93.

18. Lock S, Smallman M, Lee M, Rydin Y. "Nuclear energy sounded wonderful 40 years ago": UK citizen views on CCS. Energy Policy. 2014;66:436-49.

19. Braun C. Not in my backyard: CCS sites and public perception of CCS. Risk Anal. 2017;37(12):2264-75.

20. Gough C, Garcia-Freites S, Jones C, Mander S, Moore B, Pereira C, et al. Challenges to the use of BECCS as a keystone technology in pursuit of $1.5^{\circ} \mathrm{C}$. Global Sustainability. 2018;1:e5.

21. Haug JK, Stigson P. Local acceptance and communication as crucial elements for realizing CCS in the Nordic region. Energy Procedia. 2016;86(Supplement C):315-23.

22. Gough C, Cunningham R, Mander S. Understanding key elements in establishing a social license for CCS: an empirical approach. Int J Greenh gas con. 2018;68:16-25.

23. Gough C, O'Keefe L, Mander S. Public perceptions of CO2 transportation in pipelines. Energy Policy. 2014;70(0):106-14 This paper explores how perceptions of BECCS are influenced by the choice of policy mechanism used to incentivise its deployment, showing that attitudes to the technology may be strongly influenced by the choice of policy through which is supported.

24. Shackley S, Dowd A-M, Scott V, Howell R, Markusson N, Boot K, et al. Key messages for communication needs for key stakeholders. Cheltenham: IEAGHG; 2013. March 2013. Contract No.: 2013/7. 
25. Bellamy R, Lezaun J, Palmer J. Perceptions of bioenergy with carbon capture and storage in different policy scenarios. Nat Commun. 2019;10(1):743

26. L'Orange Seigo S, Arvai J, Dohle S, Siegrist M. Predictors of risk and benefit perception of carbon capture and storage (CCS) in regions with different stages of deployment. Int J Greenh gas con. 2014;25:23-32.

27. Haarstad H, Rusten G. The challenges of greening energy: policy/ industry dissonance at the Mongstad refinery, Norway. Environ plann c. 2016;34:340-55.

28. Mabon L, Shackley S, Bower-Bir N. Perceptions of sub-seabed carbon dioxide storage in Scotland and implications for policy: a qualitative study. Mar Policy. 2014;45:9-15.

29. Mabon L, Shackley S, Blackford JC, Stahl H, Miller A. Local perceptions of the QICS experimental offshore $\mathrm{CO} 2$ release: results from social science research. Int J Greenh gas con. 2015;38:18-25.

30. Thomas G, Pidgeon N, Roberts E. Ambivalence, naturalness and normality in public perceptions of carbon capture and storage in biomass, fossil energy, and industrial applications in the United Kingdom. Energy Res Soc Sci. 2018;46:1-9.

31. Coyle FJ. 'Best practice' community dialogue: the promise of a small-scale deliberative engagement around the siting of a carbon dioxide capture and storage (CCS) facility. Int J Greenh gas con. 2016;45:233-44.

32. van Os HWA, Herber R, Scholtens B. Not under our back yards? A case study of social acceptance of the Northern Netherlands CCS initiative. Renew Sust Energ Rev. 2014;30(0):923-42.

33. Pietzner K, Schwarz A, Duetschke E, Schumann D. Media coverage of four carbon capture and storage (CCS) projects in Germany: analysis of 1,115 regional newspaper articles. Energy Procedia. 2014;63(Supplement C):7141-8.

34. Vögele S, Rübbelke D, Mayer P, Kuckshinrichs W. Germany's "No" to carbon capture and storage: just a question of lacking acceptance? Appl Energy. 2018;214:205-18.

35. Boyd AD, Hmielowski JD, David P. Public perceptions of carbon capture and storage in Canada: results of a national survey. Int $\mathrm{J}$ Greenh gas con. 2017;67(Supplement C):1-9.

36. Karimi F, Toikka A, Hukkinen JI. Comparative socio-cultural analysis of risk perception of carbon capture and storage in the European Union. Energy Res Soc Sci. 2016;21:114-22.

37. Feenstra CFJ, Mikunda T, Brunsting S. What happened in Barendrecht? Case study on the planned onshore carbon dioxide storage in Barendrecht, the Netherlands: CSIRO; 2010.

38. Renner M. Carbon prices and CCS investment: a comparative study between the European Union and China. Energy Policy. 2014;75: 327-40.

39. Chen Z-A, Li Q, Liu L-C, Zhang X, Kuang L, Jia L, et al. A large national survey of public perceptions of CCS technology in China. Appl Energy. 2015;158:366-77.

40. Yang L, Zhang X, McAlinden KJ. The effect of trust on people's acceptance of CCS (carbon capture and storage) technologies: evidence from a survey in the People's Republic of China. Energy. 2016;96:69-79.

41. Hall N, Lacey J, Carr-Cornish S, Dowd A-M. Social licence to operate: understanding how a concept has been translated into practice in energy industries. J Clean Prod. 2015;86:301-10.

42. Asayama S, Ishii A. Selling stories of techno-optimism? The role of narratives on discursive construction of carbon capture and storage in the Japanese media. Energy Res Soc Sci. 2017;31:50-9.

43. Feldpausch-Parker A, Burnham M, Melnik M, Callaghan M, Selfa T. News media analysis of carbon capture and storage and biomass: perceptions and possibilities. Energies. 2015;8(4):3058-74.

44. Burns W, Nicholson S. Bioenergy and carbon capture with storage (BECCS): the prospects and challenges of an emerging climate policy response. J Environ Stud Sci. 2017;7(4):527-34.
45. Lofstedt R. Effective risk communication and CCS: the road to success in Europe. J Risk Res. 2015;18(6):675-91.

46. Popova OH, Small MJ, McCoy ST, Thomas AC, Karimi B, Goodman A, et al. Comparative analysis of carbon dioxide storage resource assessment methodologies. Environ Geosci. 2012;19(3):105-24.

47. Herzog H, Wolff J. What lessons can hydraulic fracturing teach CCS about social acceptance? Energy Procedia. 2014;63:7024-42.

48. Jasanoff S, Kim S-H. Containing the atom: sociotechnical imaginaries and nuclear power in the United States and South Korea. Minerva. 2009;47(2):119.

49. Geden O, Peters GP, Scott V. Targeting carbon dioxide removal in the European Union. Clim Pol. 2019;19(4):487-94.

50. Scott V, Geden O. The challenge of carbon dioxide removal for EU policy-making. Nat Energy. 2018;3(5):350-2.

51. Society R. Geoengineering the climate: science, governance and uncertainty. 2009 September 2009. Contract No.: RS policy document 10/09.

52. Vaughan N, Lenton T. A review of climate geoengineering proposals. Clim Chang. 2011;109(3-4):745-90.

53. Bellamy R, Lezaun J, Palmer J. Public perceptions of geoengineering research governance: An experimental deliberative approach. Glob Environ Chang. 2017;45:194-202.

54. Bellamy R, Chilvers J, Vaughan NE. Deliberative mapping of options for tackling climate change: citizens and specialists 'open up' appraisal of geoengineering. Public Underst Sci. 2016;25(3):269-86.

55. Meadowcroft J. Exploring negative territory carbon dioxide removal and climate policy initiatives. Clim Chang. 2013;118(1):137-49.

56. Lomax G, Workman M, Lenton T, Shah N. Reframing the policy approach to greenhouse gas removal technologies. Energy Policy. 2015;78(0): 125-36

57. Lenzi D. The ethics of negative emissions. Glob Sustain. 2018;1:e7 This paper uses empirical data from interviews with modelers and policy experts to unpack the ethical implications and normative choices inherent in the modelled pathways of BECCS/ CDR, recommending a 'purposeful modelling' approach to coproduce results, giving greater legitimacy and transparency.

58. Cox EM, Pidgeon N, Spence E, Thomas G. Blurred lines: the ethics and policy of greenhouse gas removal at scale. Front Environ Sci. 2018;6(38)

59. Lomax G, Lenton TM, Adeosun A, Workman M. Investing in negative emissions. Nat Clim Chang. 2015;5(6):498-500.

60. Dooley K, Christoff P, Nicholas KA. Co-producing climate policy and negative emissions: trade-offs for sustainable land-use. Glob Sustain. 2018;1:e3.

61. Vaughan NE, Gough C, Mander S, Littleton EW, Welfle A, Gernaat DEHJ, et al. Evaluating the use of biomass energy with carbon capture and storage in low emission scenarios. Environ Res Lett. 2018;13(4):044014.

62. Fuss S, Canadell JG, Peters GP, Tavoni M, Andrew RM, Ciais P, et al. Betting on negative emissions. Nat Clim Chang. 2014;4(10): $850-3$.

63. Anderson K, Peters G. The trouble with negative emissions Science. 2016;354(6309):182-3.

64. Lenzi D, Lamb WF, Hilaire J, Kowarsch M, Minx JC. Don't deploy negative emissions technologies without ethical analysis. Nature. 2018;561:303-5.

65. Beck S, Mahony M. The IPCC and the new map of science and politics. Wiley Interdiscip Rev Clim Chang. 2018;9(6):e547.

66. Fridahl M, Lehtveer M. Bioenergy with carbon capture and storage (BECCS): global potential, investment preferences, and deployment barriers. Energy Res Soc Sci. 2018;42:155-65.

67. Larkin A, Kuriakose J, Sharmina M, Anderson K. What if negative emission technologies fail at scale? Implications of the Paris Agreement for big emitting nations. Clim Pol. 2017;1-25. 
68. van Vuuren DP, Stehfest E, Gernaat DEHJ, van den Berg M, Bijl $\mathrm{DL}$, de Boer HS, et al. Alternative pathways to the $1.5^{\circ} \mathrm{C}$ target reduce the need for negative emission technologies. Nat Clim Chang. 2018.

69. Fridahl M. Socio-political prioritization of bioenergy with carbon capture and storage. Energy Policy. 2017;104:89-99.

70. Thornley P, Mohr A. Policy frameworks and supply-chain accounting. In: Gough C, Thornley P, Mander S, Vaughan N, Lea-Langton A, editors. Biomass Energy with Carbon Capture and Storage (BECCS): Unlocking Negative Emissions: John Wiley \& Sons Ltd; 2018.

71. Boucher P, Gough C. Mapping the ethical landscape of carbon capture and storage technology. Poiesis Prax. 2012;9(3-4):249-70.

72. Gough C, Boucher P. Ethical attitudes to underground CO2 storage: points of convergence and potential faultlines. International Journal of Greenhouse Gas Control. 2013;13:156-67.

73. Mabon L, Shackley S. Meeting the targets or re-imagining society? An empirical study into the ethical landscape of carbon dioxide capture and storage in Scotland. Environ Values. 2015;24(4):465-82.

74. Fajardy M, Chiquier S, Mac DN. Investigating the BECCS resource nexus: delivering sustainable negative emissions. Energy Environ Sci. 2018.

75. Markusson N, McLaren D, Tyfield D. Towards a cultural political economy of mitigation deterrence by negative emissions technologies (NETs). Glob Sustain. 2018;1:e10.

76. Gamborg C, Anker HT, Sandoe P. Ethical and legal challenges in bioenergy governance: coping with value disagreement and regulatory complexity. Energy Policy. 2014;69(Supplement C):326-33.

77. Creutzig F, Corbera E, Bolwig S, Hunsberger C. Integrating placespecific livelihood and equity outcomes into global assessments of bioenergy deployment. Environ Res Lett. 2013;8(3):035047.

78. Reynolds JL. The politics and governance of negative emissions technologies. Glob Sustain. 2018;1:e12.

79. Geden O, Scott V, Palmer J. Integrating carbon dioxide removal into EU climate policy: Prospects for a paradigm shift. Wiley Interdiscip Rev Clim Chang. 2018;0(0):e521.
80. Creutzig F. Economic and ecological views on climate change mitigation with bioenergy and negative emissions. GCB Bioenergy. 2014;n/a-n/a.

81. Honegger M, Reiner D. The political economy of negative emissions technologies: consequences for international policy design. Clim Pol. 2018;18(3):306-21.

82. Cox E, Edwards NR. Beyond carbon pricing: policy levers for negative emissions technologies. Clim Pol. 2019;1-13.

83. Torvanger A. Governance of bioenergy with carbon capture and storage (BECCS): accounting, rewarding, and the Paris agreement. Clim Pol. 2019;19(3):329-41.

84. Gilbert A, Sovacool BK. Emissions accounting for biomass energy with CCS. Nat Clim Chang. 2015;5:495.

85. Platt D, Workman M, Hall S. A novel approach to assessing the commercial opportunities for greenhouse gas removal technology value chains: developing the case for a negative emissions credit in the UK. J Clean Prod. 2018;203:1003-18.

86. Peters G, Geden O. Catalysing a political shift from low to negative carbon. Nat Clim Chang. 2017;7(September 2017).

87. Zakkour P, Kemper J, Dixon T. Incentivising and accounting for negative emission technologies. Energy Procedia. 2014;63:6824-33.

88. Carattini S, Kallbekken S, Orlov A. How to win public support for a global carbon tax. Nature. 2019(16 January 2019).

89. McLaren DP, Tyfield DP, Willis R, Szerszynski B, Markusson NO. Beyond "Net-Zero": a case for separate targets for emissions reduction and negative emissions. Front Clim. 2019;1(4).

90. Renn O, Webler T, Wiedemann P, editors. Fairness and competence in citizen partipation: evaluating models for environmental discourse. Springer; 1995.

Publisher's Note Springer Nature remains neutral with regard to jurisdictional claims in published maps and institutional affiliations. 